\title{
An investigation of the Performance of a Conical Solar Water Heater in the Kingdom of Bahrain
}

\section{Nessreen Gaaliche}

Department of Mechanical

Engineering,

College of Engineering,

University of Bahrain,

PO Box 32038, Kingdom of Bahrain

ngaaliche@uob.edu.bh
Teoman Ayhan

Department of Mechanical

Engineering,

College of Engineering,

University of Bahrain,

PO Box 32038, Kingdom of

Bahrain

tayhan@uob.edu.bh
Raouf Fathallah

Department of Mechanical

Engineering,

National Engineering School

of Sousse,

University of Sousse

PO Box 264, Sousse Erriadh 4023

\begin{abstract}
Domestic water heater corresponds to $25 \%$ of the house energy consumption and can play an important role to reduce energy house expenses. Solar energy offers a preferred renewable energy resource because of its economic and environmental advantages. It is considered the best alternative to reduce domestic water heater energy consumption cost. Converting solar energy into heat can be considered among the simplest used systems. Solar thermal conversion is more efficient than solar electrical direct conversion method. Solar water heater systems are particularly easy to use and to repair. The integrated conical solar collector water heater (ICSCWH) is so far the easiest among water heating systems. The ICSCWH converts directly and efficiently the solar flux into heat. In order to expand the utilization of ICSCWH systems, many design modifications have been examined and analyzed. This study provides an experimental investigation and mathematical simulation of an ICSCWH system equipped with a glass cover resulting in the increase of the maximum absorption. Integrating the cone-shaped heat collector with an aluminum spiral pipe flow system may enhance the efficiency of the proposed system. In order to maximize the solar radiation of the system, the solar water heater has been designed in a conical shape, which removes the need to change its orientation toward the sun to receive the maximum sun radiation during the day. In this system, the heating of water has been obtained using the spiral pipe flow without the use of the solar cells and mirrors in order to reduce the total cost. The storage water tank of this system is coupled with a conical solar collector. Based on the above design, the solar water heater has been fabricated and tested. In addition, an analytical modeling approach aiming
\end{abstract}


to predict the flow rate within the conical integrated collector storage solar water heater (ICSSWH) and its efficiency, was developed. Modeling through a numerical simulation approach based on energy equations was performed. Considering the entire water amount and the total area of the cone, the amount of water (facing the sun per unit absorbing area in the two symmetrical parts of the system) is found to increase, which is expected to reach a maximum water temperature at a high performance. Our experimental findings show that the daily performance is around $32 \%$ and the highest water temperature of about $45^{\circ} \mathrm{C}$ is obtained in the system at $4 \mathrm{pm}$, according to seasons and weather conditions. An efficient and simple mathematical simulation approach for the new conical solar water heater is described then validates using experimental data.

Keywords: Solar water heater, Spiral pipe flow, conical shape collector, Collectorstorage, Thermal efficiency.

\section{Introduction}

In order to enhance the performance of a heating system, we need to optimize firstly the optical performance of the system by maximizing the absorbing parameters of the surface [2], then the efficiency of energy storage tank by maximizing the density of thermal storage $[4,5]$, this means smaller volume and low building cost, as well as a good heat transfer in the system [15,9]. Kalogirou [6] describes in details the existing solar collectors explaining by type its thermal transfer and its different applications, leading to many innovations in the area of solar collectors like the photovoltaic-thermal collectors. In addition, it is important to highlight the great importance of the role of the storage reservoir design. Tyagi et al. [14] showed that the convection heat between the receiver surface and the ambient air decreases the performance of the system. For example, Kumar and Rosen [7] and El-Sebaii [3] proposed the integration of an insulation cover for night application with the purpose of conserving the temperature of hot water inside the storage vessel. Also Zhao, $\mathrm{Lu}$ and Tian [16] propose the use of insulation made from transparent material. In addition, Sefa T. et al. [8] pointed out the application of different types of special phase change materials in storage ICSWH. Several researchers studied the cylindrical design of storage reservoir because they are more found suitable for high water pressure [13]. Whereas; they proposed the use of trapezoidal storage tank as a solution for the stratification phenomenon in the water reservoir [1].

An experimental study was carried out by Smyth et al. [10] to investigate a novel inverted absorbing ICSSWH installed in the parabolic concentrator composed of a second cylindrical reflector. Both optical and thermal transfer were analyzed in details. In a modified design [11], the water storage vessel consisted of two different sections, an upper part which presenting the one third of total volume of the water is 
totally covered by a vessel insulation, while the bottom consisting of the rest of the total volume is subjected to the incident solar irradiation. This configuration was found to conserve very well the heat due to the use of the transparent insulation. Sridhar and Reddy [11] invented a new cuboid shape of water storage vessel totally insulated, in which the receiver and the storage vessel present the same section in order to reduce the thermal loss during the non-collection periods. Suhas Vet al. [12] designed and tested an inverse conical-type solar heater. In the conical water tank, the sand was placed in contact with the surface of the sheet metal and the conical frame which improve the efficiency of the system. The tubes of water were placed inside the water vessel. The highest heat was obtained between 2 to $3 \mathrm{pm}$. In the literature, many solutions can be found such as the use of one or more transparent covers, a selective absorbing surface, and excellent insulation of the non-illuminated vessel parts in order to solve the problems of the utilization of this type of solar water heater.

In our case, we proposed also the solution of integrating the cone-shaped heat collector with an aluminum helical pipe. To achieve the objectives, firstly a mathematical model and analytical simulation of the integrated conical solar collector water heater (ICSCWH) were developed.

The simulation method was used in order to examine the daily performance of an ICSCWH for the month of May, and then compared with the experimental data. The simulation of performance was found to be perfectly consistent with experiment results.

\section{System design}

A new solar water heating system is proposed for operation in the Kingdom of Bahrain climate conditions. The novel ICSCWH system is principally composed of a conical collector and a storage vessel. The solar collector has a collecting surface facing to solar radiation and water supply to be heated and thermally coupled with the collecting plate. A part of the incident solar radiation in the collecting surface is absorbed and increases its temperature; thermal energy circulates from the collecting surface into the water. In fact, the present system is a solar water heater containing a conical structure and an aluminum helical pipe disposed vertically within the conical structure.

It can decrease the use of oil particularly in developing countries. The experimental set-up of ICSCWH system was installed at the Mechanical Laboratory of the University of Bahrain. The Kingdom of Bahrain has a latitude of $26^{\circ} \mathrm{N}$ and a longitude of $50.5^{\circ} \mathrm{E}$. In our system, the conical collector is fabricated to receive the solar irradiation by the absorbing surface then converts the sunlight into heat. The sun energy peaks at local noon and then decreases significantly. Insulated water vessel at the bottom side could minimize thermal losses particularly during night. 
Figure 1 describes in detail each component of the ICSCWH system. Figure 2 shows a photograph of the ICSCWH experimental set-up.

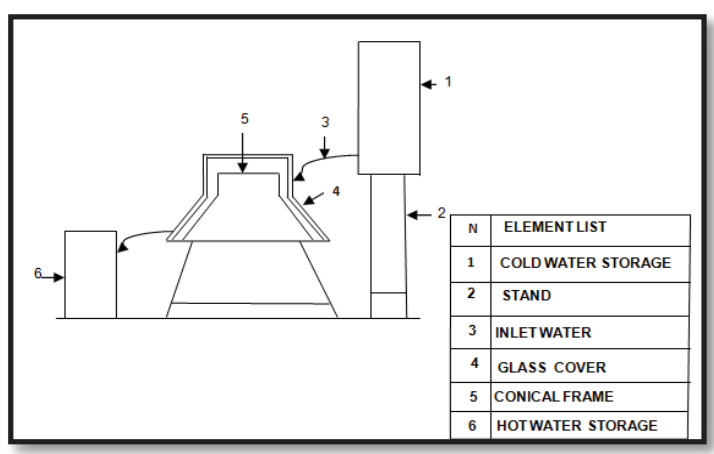

Fig.1 Line diagram of solar water heater.

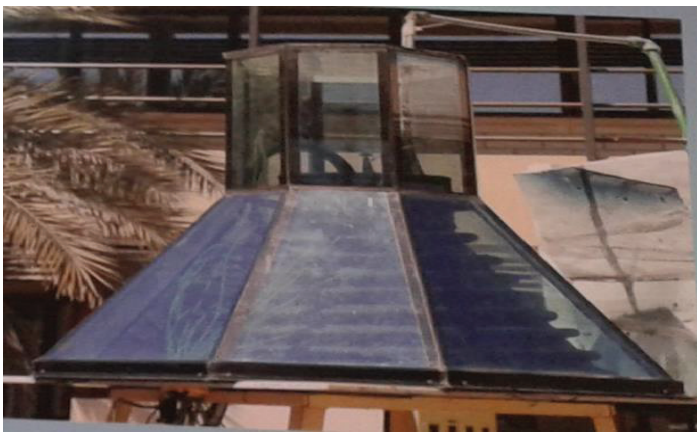

Fig.2 Photograph of the Experimental Set-up of ICSCWH system at the University of Bahrain.

The water circulates in a closed loop system. By allowing the hot water to flow in a spiral-type aluminum pipe and dumped into the conical tank constantly, the water starts to receive some of the heat generated via solar radiation, thus increasing the water temperature.

\section{Modeling and Simulation: Analytical Approach}

\subsection{Analytical Analysis of the System}

Kumar and Rosen [7] showed that the modified integrated collector-storage solar water heater (ICSSWH) with extended storage unit will improve the heating efficiency. The water circulates from sections A to B and vice versa during collection periods. Natural convection in section A is developed as a result of buoyancy force. For simplification, each symmetrical-section of the system is studied separately. Given the symmetry of velocity field lines, the system is considered in the following approach, as shown in figure 3. 


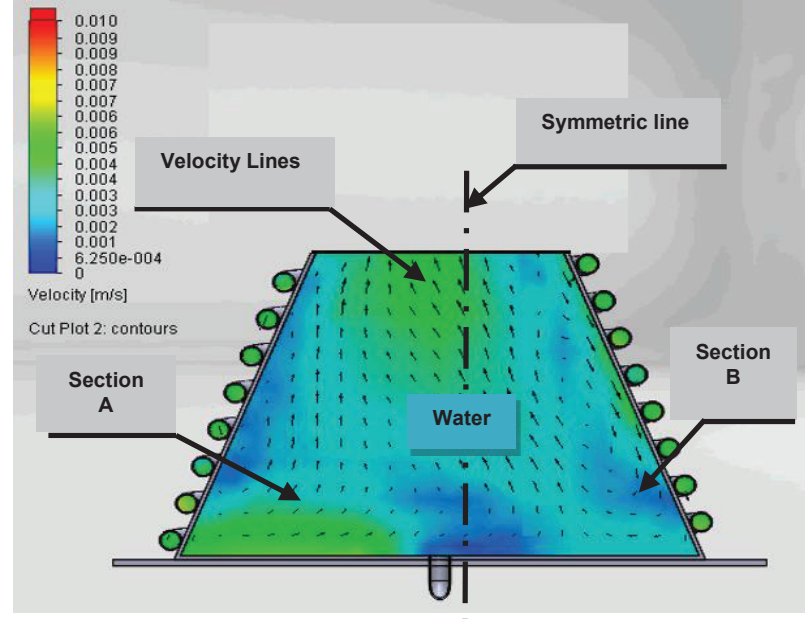

Fig.3 3-D Representation of velocity simulation of the system with natural flow.

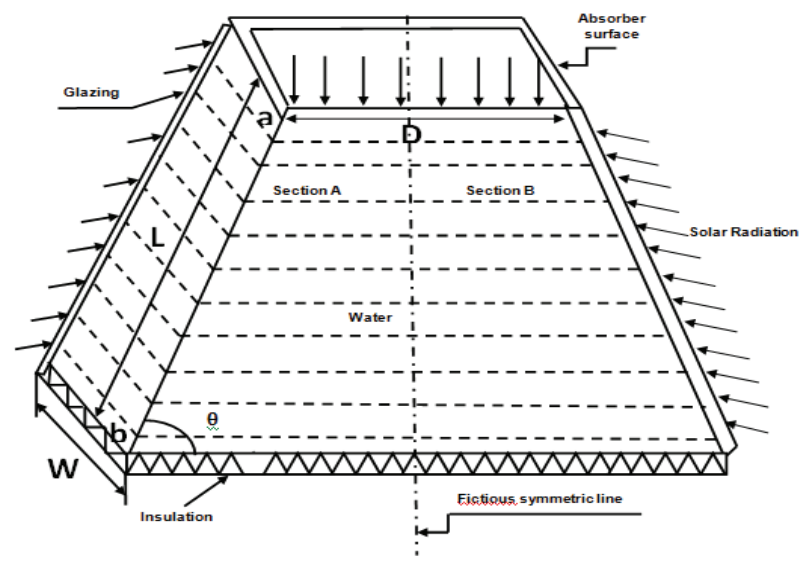

Fig.4 Description of approximate conical ICSCWH

(a):upper side of section A;(b): lower side of section $A ;(D)$ : diameter of the upper side of the cone; $(\mathrm{W})$ : depth of section $\mathrm{A} ;(\theta)$ : inclination angle.

An equation is developed for natural convection flow rate in section A. In addition, to calculate the temperature of water and the efficiency, the energy equations are obtained for section A and solved using analytical simulation. The total water volumes of the two symmetrical-sections are designed to maximize thermal efficiency.

In order to study the influence of climatic and operation conditions on the efficiency of the simplified ICSCWH system described in Figure 4, energy equations are conducted for section A only without considering section B. But, for the entire volume of water and the whole surface, the heat is transferred in section $\mathrm{A}$ and section $\mathrm{B}$ via natural convection. To determine the thermal transfer in section $\mathrm{A}$, an equation is established for natural convection flow rate resulting from buoyant forces. The mathematical calculation mentioned below for natural convection flow rate is the same of two parallel inclined surfaces separated by a fixed distance as reported by Kumar and Rosen [7]. 
Section A is modeled as a rectangular section composed of two parallel surfaces inclined by an angle $\theta$ and separated by a constant distance W. For the calculation of natural convection flow rate, different hypothesis are taken into consideration:

1) The temperature of water is variable along the direction of length $L$;

2) The continuity and uniformity of the variation of water temperature from the bottom to the top;

Our modified design section A only with the top section without insulation;

3) The total water storage volume is distributed such that $50 \%$ is in section A and $50 \%$ in section $\mathrm{B}$,

4) All the thermal and physical properties of water (except density) are not variable, In our methodology, the calculation performed by Kumar and Rosen [7] is adopting by considering some appropriate modifications.

In Figure 4, the pressure difference in sections A caused by buoyancy force is noted $\Delta \mathrm{p}_{\mathrm{a}-\mathrm{b}}$ which represents the pressure difference in section A between two surfaces a and $b$.

The difference of pressure in section $\mathrm{A}, \Delta \mathrm{p}_{\mathrm{a}-\mathrm{b}}$ is determined by:

$$
\Delta p_{a-b}=\mathrm{g} \sin \theta \int_{0}^{L}\{\rho 1-\rho(y)\} \mathrm{dy}
$$

where $g$ is the gravitational acceleration, $\theta$ is the inclination angle of section $A, \rho 1$ is the water density at the bottom, $\mathrm{L}$ is the total length of the section $\mathrm{A}$ and $\rho(\mathrm{y})$ is the water density at a distance $y$ from the bottom in the direction $\mathrm{L}$.

The equation describing the natural convection mass flow rate $\dot{m}$ and the useful energy $\dot{Q}_{u}$ to section A which is equal to the difference between the input energy and the lost energy is developed as follow:

$$
\begin{aligned}
& \dot{m} c_{w}\left(T_{2}-T_{1}\right)=\dot{Q_{u}}=\dot{Q_{l n}}-\dot{Q}_{l} \\
& \dot{m}=\left[\frac{W^{3} \mathrm{~g} \beta \rho_{0}\left(Q_{i n}-\dot{Q}_{L}\right) B_{1}}{12 v c_{w}} \frac{\sin \theta}{2}\right]^{\frac{1}{2}}
\end{aligned}
$$

This equation for the natural convection flow rate in section $\mathrm{A}$ of a simplified ICSCWH heating system is obtained by heat transfer from section A to B from morning until noon time and vice versa from noon time until 4 p.m. Equation (3) indicates that the most significant factor influencing the flow rate on the depth $\mathrm{W}$ of section A. From noon time until 4 p.m, reverse convection thermal transfer is generated from section $\mathrm{A}$ to $\mathrm{B}$, but at a slower rate, as a result of the drop of temperature gradient and gravity.

\section{Energy Balance for Section A}


Section $A$ is considered as a rectangular ICSSWH. Using the first law of thermodynamics, transient energy balances are developed for the absorbing plate and water.

In our case, an absorber surface is added in the top side of section A. As a result, energy equations for the absorber surface and water can be written respectively as follows:

$$
\begin{aligned}
& m_{p} c_{p} \frac{d T_{p}}{d t}=(\alpha \tau)_{e} I_{t} A_{p}+(\alpha \tau)_{e} I_{t}\left(\frac{\pi \mathrm{D}^{2}}{4}\right)-U_{t}\left(T_{p}-T_{a}\right) A_{p}-h_{p w A}\left(T_{p}-T_{w A}\right) A_{p} \\
& m_{w A} c_{w} \frac{d T_{w A}}{d t}=h_{p w A}\left(T_{p}-T_{w A}\right) A_{p}
\end{aligned}
$$

with, $T_{p}$ the temperature of the absorbing surface, $T_{w A}$ the water temperatures in section $\mathrm{A}, T_{a}$ the surrounding air temperature, $h_{p w A}$ the thermal transfer coefficient from the absorbing plate to water, $U_{t}$ the top thermal transfer coefficient from the absorbing plate to the surrounding air, $I_{t}$ the total solar intensity, $(\alpha \tau)_{e}$ the effective transmittance-absorbance product for the absorbing plate, and $\dot{m}$ the natural convection flow rate. In addition, $A_{p}$ the absorber area of the top side of section $A$, $m_{w A}$ the mass of water in section $\mathrm{A}, m_{p}$ the mass of the absorber surface, and $c_{p}$ and $c_{w}$ are the specific heats of the absorber plate and the water, respectively.

The left parts of Eqs. (4) and (5) respectively represent the changes with time of energy inside of the absorber surface and the water.

\section{Efficiency of Water Heater}

The thermal efficiency of this conical solar water heater is defined as:

$$
\eta=\frac{Q}{\int_{0}^{t} I_{t} d t\left(A+\left(\frac{\pi D^{2}}{4}\right)\right)}
$$

The numerator of Eq. (6) describes the gain of useful thermal energy generating by this system, whereas the denominator describes the incident solar energy during the operating time by the total area of the system.

\section{Results and Discussion}

The simulations are performed for the climatic conditions of the Kingdom of Bahrain. The ICSCWH system is useful for seasonal applications in the Kingdom of Bahrain. The hourly variations of solar intensity for May in the Kingdom of Bahrain is considered for our numerical simulation (see Figure 5). To compute the water and absorbing surface temperatures, the two differential coupled equations (4) and (5) that describe the transient behavior of solar gain energy and heat loss of the system are resolved. The analytical model has been solved numerically. The numerical simulation of the novel conical solar integrated-collector-storage system has been realized. The analytical simulations with glass cover are carried out to the three different dimensional cases. 
Figure 6 shows that the flow rate increases as the solar radiation rises; which is faster in the period 9 a.m-11 a.m and slower at noon time. Based on figure 5 and figure 6 , it is important to mention that the flow rate increases as the solar radiation increases. During solar irradiance 9 a.m-13 p.m, a continuous raise is examined in the natural convection flow rate; nevertheless the temperature in the absorbing plate diminished as the solar flux decreases from 13 p.m to 16 p.m.

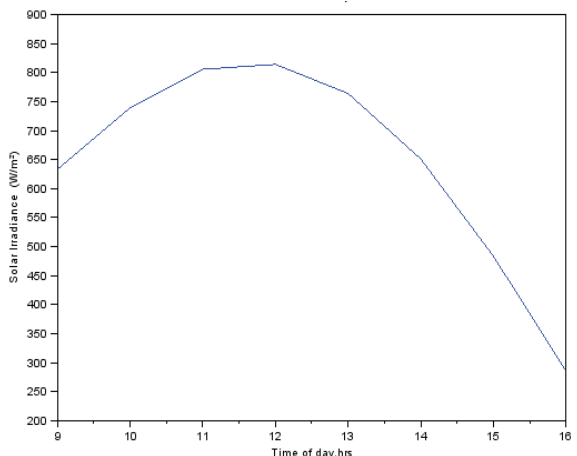

Fig.5 Hourly variation in solar intensity in Bahrain for 10 May.

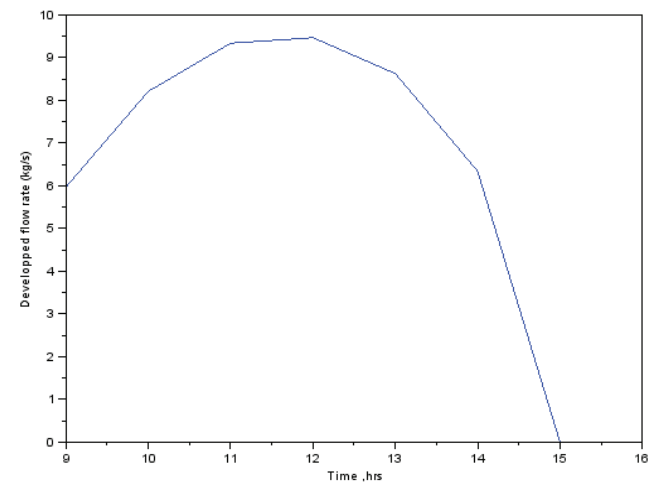

Fig.6 Simulation of natural convection flow rate.

From Figure 7, it can be concluded that as the volume ratio $\mathrm{S} / \mathrm{V}$ increases, the estimated water temperatures increase. So, a case study 1 representing our investigated system has the highest output water temperature. Similarly, the volume ratio $\mathrm{S} / \mathrm{V}$ increases, the inclination angle raises. The temperature of hot water increases of about $6^{\circ} \mathrm{C}$ as the inclination angle changesfrom $60^{\circ}$ to $68^{\circ}$ (study cases 1 and 2). Thus, the tilt angle in our study case 1 for sections A and B generates the highest heat from the system for the climatic conditions in the Kingdom of Bahrain is $68^{\circ}$.

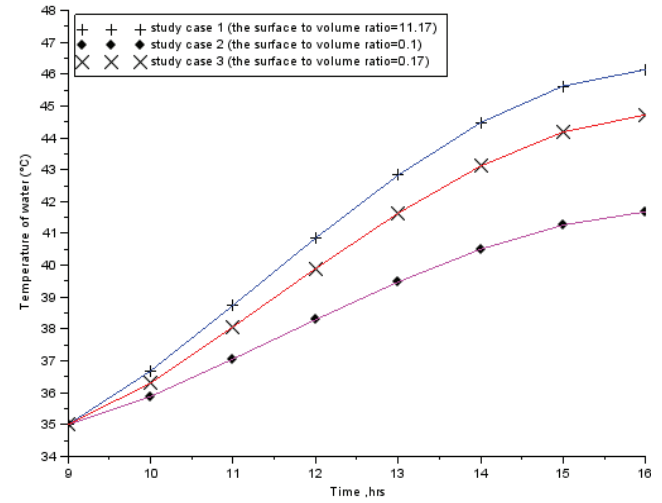


Fig.7 Comparison between simulated water temperatures for different surface to volume ratio $(\mathrm{S} / \mathrm{V})$.

\section{Experimental Verification of the Mathematical Model}

To verify the developed mathematical model, a comparison by means of an experimental approach is carried out. The difference between experimental and simulation results of water temperatures are resulted to the different approximations and error's of the instrument used in this research. Figure 9 shows that the temperature of collector at noon can reach $56^{\circ} \mathrm{C}$. The difference between the water and surface temperature is resulted to the convection loss between the absorbing plate surface and water.

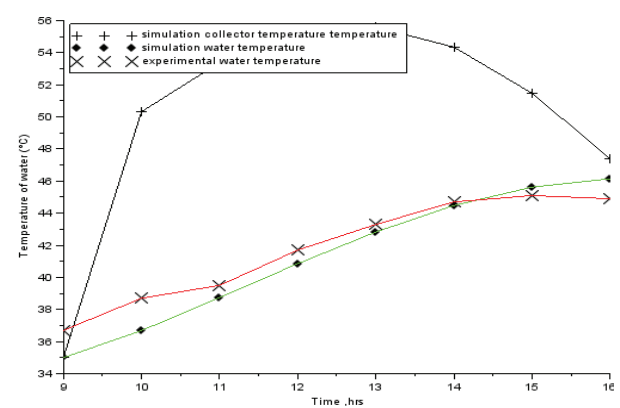

Fig.9 Validation of the numerical results with experiments.

In Figure 10, the variation of efficiency of the system between experimental and simulation results is plotted versus time on a selected day; i.e. 10, May 2015. It can be concluded that the highest efficiencies of the system are respectively around $32.75 \%$ and $30.57 \%$, respectively.

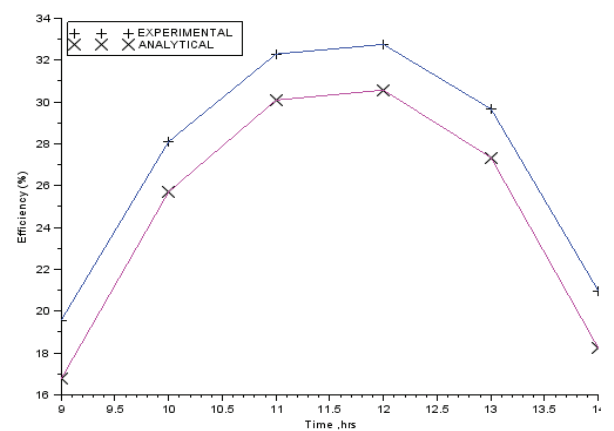

Fig.10 Comparison between experimental and simulation efficiencies for natural flow with glass.

Figure 11 presents the experimental and simulation useful energy which has the same behavior of the efficiency. The variation of experimental and simulation useful 
energy variation of the system is reported for a selected day 10 May 2015. It can be concluded that the optimum useful energy of the system is equal to 0.33 and 0.37 $\mathrm{Kw}$, respectively.

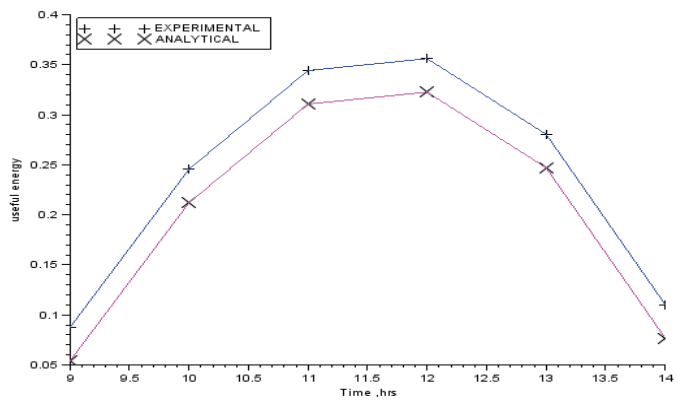

Fig.11 Comparison between experimental and simulation useful energy in $\mathrm{Kw}$ natural convection with glass.

From the above obtained results, it can be concluded that the developed analytical model is consistent. The analytical model is based on energy balances obtained from the first law of thermodynamic. The difference between the simulation and experimental results is mainly caused by instrumental errors $\left(2^{\circ} \mathrm{C}\right)$. The natural convection flow rate increases with the solar intensity, reaching a maximum value at noon time. Also, the highest efficiency and thermal output are achieved at noon time when the solar irradiation reaches a maximum value. The highest efficiency for an experimental system is observed for $\mathrm{S} / \mathrm{V}$ ratio 11.7.

\section{Conclusion}

The objective of this research work is developed to the investigation of thermal efficiency of an integrated conical solar collector water heater in the Kingdom of Bahrain. The numerical simulation of the system is performed for the determination of hourly variation. So, different parameters such as water and surface absorbing temperatures, natural convection flow rate, useful energy and efficiency. Therefore, the following findings are very helpful for the design of solar water heater:

$\checkmark$ Temperature of the ambient air, water and absorber surface rise with time of the day and achieve higher temperature after 7 hours of operation due to the rise in solar intensity.

$\checkmark$ The temperature of absorber surface is greater than the water surface. 
$\checkmark$ Increasing the volume ratio $\mathrm{S} / \mathrm{V}$ affects significantly the output water temperature.

$\checkmark$ Raising the inclination of angle affects significantly the water temperature.

$\checkmark$ The use of glass cover to enhance the optical coefficient of absorbing surface results in the enhancement of the thermal output of the system.

$\checkmark$ It is found that the total daily performance is about $32 \%$, according to weather and operating conditions.

\section{References}

(1) Cruz J.M.S., P.H. Geoffrey and J.P.S.R. Albino, "Thermal performance of a trapezoidalshaped solar collector/energy store", Applied Energy , 2002; 73: 195-212.

(2) De Winter F. "Solar collectors, energy storage, and materials". Massachusetts: The MIT press; 1991.

(3) El-Sebaii A.A., "Thermal performance of a shallow solar pond integrated with a baffle plate", Applied Energy; 2005: 81-33e53.

(4) Farid M.M., Khudhair A.M., Razack S.A.K. and Al-Hallaj S. "A review on phase change energy storage: materials and applications". Energy Convers Manage. 2004; 45:1597-615.

(5) Gil A, Medrano M, Martorell I, Lazaro A, Dolado P, Zalba B, et al. "State of the art on high

(6) temperature thermal energy storage for power generation. Part 1 - concepts, materials and

(7) modellization". Renew Sust Energy Rev 2010; 14:31-55.

(8) Kalogirou SA. "Solar thermal collectors and applications".Prog Energy Combust, 2004; 30:231-95.

(9) Kumar R., M.A. Rosen, "Integrated collector storage solar water heater with corrugated absorber surface", Applied Thermal Engineering ,2010; 30 :1764-1768.

(10) Sefa T., S., A.M. Hakan, "Temperature distributions in trapezoidal built in storage solar water heaters with/without phase change materials", Energy Conversion and Management, 2006; 47, 2143-2154.

(11) Sharma A, Tyagi VV, Chen CR, Buddhi D. "Review on thermal energy storage with phase change materials and applications". Renew Sust Energy Rev 2009; 13:318-45.

(12) Smyth M., P.C. Eames, B. Norton, "Heat retaining integrated collector/storage solar water heaters", Solar Energy, 2003;75:27-34.

(13) Sridhar A., and K.S. Reddy. "Transient analysis of modified cuboid solar integrated collector-storage Ahmet system", Applied Thermal Engineering. 2007:27-330e346.

(14) Suhas, SukeerthCalastawad, Sawan Kumar, Purujeeth and Shyam Sharma (2015)"performance of a conical shaped solar water heater with that of a conventional solar water heater", International Research Journal of Engineering and Technology. Vol.02 (4), pp 800-803.

(15) Tripanagnostopoulos Y. and P. Yianoulis, "Integrated Collector-Storage Systems With Suppressed Thermal Losses”, Solar Energ, 1992 ; 48: 1: 31-43.

(16) Tyagi S.K., W. Wang, S.C. Kaushik, M.K. Singhal and S.R. Park, "Energy analysis and parametric study of concentrating type solar collectors", International Journal of Thermal Sciences. 2007;46 :1304-1310. 
(17) Zalba B, Marin JM, Cabeza LF, Mehling H. "Review on thermal energy storage with phase change: materials, heat transfer analysis and applications". ApplThermEng, 2003; $23: 251-83$.

(18) Zhao CY, Lu W, Tian Y. "Heat transfer enhancement for thermal energy storage using metal foams embedded within phase change materials (PCMs)". Sol Energy, 2010; 84:1402-12. 